Asia Pacific Journal of Contemporary Education and Communication Technology

ISBN (eBook): 9780994365682 । ISSN : 2205-6181

Year: 2018 , Volume: 4, Issue: 1

\title{
THE ROLE AND NATURE OF SCRM IN AUSTRALIAN PRIVATE SECTOR: AN EXPLORATORY STUDY
}

\author{
Kritcha Yawised a, Leonie Ellis ${ }^{\mathrm{b}}$, Ming Chao Wong c \\ abc University of Tasmania, Hobart, Australia \\ Corresponding email: Kritcha.Yawised@utas.edu.au
}

\begin{abstract}
Social Customer Relationship Management (SCRM) is an emerging concept that includes strategies, processes and technologies to link social media with the existing approach to traditional CRM. It is a corporate strategy for engagement with customers rather than simply a technology upgrade and not a replacement of traditional CRM. Even though the body of knowledge on the subject is vast, it is scatted due to the lack of research on this topic, especially in Australia. This paper reports a survey-based study conducted to investigate the current level of SCRM adoption by Australian companies, including the objectives for SCRM adoption, types of social media used with SCRM, SCRM implementation-related activities and barriers related to SCRM implementation at the early stage, using a sample of 1,060 Australian companies (comprising 597 SCRM adopters and 473 SCRM non-adopters). The findings highlight that SCRM adoption has been relatively superficial and usually not supported by a formal integrated strategy and policy framework. Even so, it appears that Australian companies are increasingly taking advantage of social media to manage customer relationships. This study serves as a starting point for research into SCRM implementation in the private sector to build up confidence among shareholders and investors for adopting such initiatives.
\end{abstract}

Keywords: Social Customer Relationship Management (SCRM), Social Media, CRM, Australian Private Sector.

\section{Introduction}

The role of Information and Communication Technology (ICT) as a basic business model has become increasingly important for businesses in the recent years as the Internet becomes more pervasive in the new global economy through realising and maximising Customer Relationship Management (CRM) opportunities presented by the emergence of social media (Komito, 2011). Through online communication which is related to social media, companies are enabled to take full advantage of potential traditional CRM toward a new CRM era (Choudhurya and Harrigan 2014). Since social media plays a vital role in supporting a corporate strategy and competitive advantage, an understanding of them can provide valuable information for the new cutting edge of CRM (Harrigan and Miles, 2014).

The term of Social Customer Relationship Management (SCRM) is introduced as a strategic business approach that combines social media technologies with CRM to bring about a superior engagement with customers and thereby increase a company's profit (Greenberg 2010). SCRM is more than simply a technology upgrade and not a replacement of traditional CRM. It entails the enhancement of a relationship in the quality and effectiveness of a company's interactions with its customers, with the aim of bringing about superior engagement with customers, providing meaningful customer experiences and building relationship (Kuepper et al, 2015). Indeed, examination of possible conditions for 
achievement of gains from SCRM adoption in global companies is a key challenge for researchers.

The research on SCRM-based knowledge in business has received significantly growing attention by academies and practitioners. Preliminary academic research efforts are beginning to be published in the US and Europe, but little rigorous academic research in SCRM has been completed in Australia (Yawised and Marshall, 2015). This paper aims to examine the current situation of SCRM phenomenon in Australian companies by exploring the current state of SCRM including company objectives for their adoption, types of social media used with SCRM, SCRM implementation-related activities and its barriers. This paper is the first attempt to empirically explore and investigate the role and nature of SCRM in Australian companies. It provides a guiding process and a possible strategic direction for Australian companies wishing to adopt and engage in SCRM initiatives.

The paper is divided into four sections: it begins with the rationale for the study based on research questions and objectives of this paper; followed by a discussion of the research method selected. The third section then reports on the research findings with a discussion of results; and the last section concludes the study with recommendations for future research directions.

\section{Literature Review}

SCRM is an emerging concept that includes strategies, processes and technologies to link social media with CRM processes (Maecker et al. 2016). In other words, SCRM is built around the existing concept of CRM which requires extensive knowledge about the customer and market needs by using social media capabilities and technologies to expand and deepen the CRM approach (Mosadegh and Behboudi, 2011). In this study, traditional CRM was defined as a business strategy that drives functional plans, processes and actions towards establishing relationships with customers, and SCRM was defined as a corporate strategy that includes the business processes and technologies to link social media or social networking sites (e.g. Facebook, LinkedIn, Twitter and etc. ) to enhance CRM.

The survey reported in this paper is part of a SCRM research project designed to explore the current SCRM adoption within the Australian companies. The overall goal of the project is to examine the role and nature of SCRM in Australian companies to assist owner managers, IT, marketing managers better understand a strategic approach to such adoption and ways for formulating relevant and effective strategies to their specific needs. The survey findings reported in this paper was designed to build a broad picture of SCRM phenomenon as a starting point before combining them together with a further in depth investigations by using qualitative interview approach. The rational and background for the present survey includes:

\subsection{What are the Objectives of SCRM Adoption by Australian Companies?}

This research question is of considerable interest as previous research indicates that the objectives of SCRM are to build 'trust' and establish customer 'loyalty' (Acker et al. 2011; Stone 2009; Woodcock et al. 2011), these overall objectives are similar to those of traditional CRM. However, the difference is that SCRM enables business organisations to better access the customer data and tools that allow more effectiveness in identifying, interacting and engaging with customers (Woodcock et al. 2011). Traditional CRM data are structured and maintained in organizational relational databases, making them much easier to manage, interpret and use for customer management purposes, while SCRM data are normally unstructured and difficult to manage, interpret and use. The distinction between routine customer data from operational silos, and big data that differs in volume, variety and velocity is a key difference between SCRM and TCRM (Buttle and Maklan, 2015). Malthouse et al. (2013) also indicates that many organisations have established a form of social presence; however, many of them lack a clear business performance objective for SCRM, particularly at the early stage of their performance measurement. At this stage, SCRM adoption tends to be used selectively within individual business functions rather than a corporate strategy where 
the objectives of such adoption are beginning to rely on the types and intensity of social media use incorporated with current CRM activities (Reinhold and Alt 2012). This could raise the question whether or not each company already have their own objectives for SCRM adoption. Therefore, this question enables the researcher to gather the data from Australian companies on their business objectives for SCRM initiatives.

\subsection{What Types of Social Media Used with SCRM and its Implications}

Recent research indicates that social media such as social networking sites (SNSs), Web2.o technology and any new social media tools and applications-are currently being employed in SCRM (Kupper et al. 2015; Malthouse et al. 2013; Maecker et al. 2016). Social media is defined as "a group of Internet-based applications that build on the ideological and technological foundations of Web 2.0 and that allow the creation and exchange of usergenerated content" (Kaplan and Haenlein2010 p.61). It offers businesses new avenues for enhancing sales and marketing as well as creating trust in customers and also helps to finds new business opportunities and share knowledge, advices and expertise (Chugh 2012; Maecker et al. 2016). Furthermore, by allowing knowledge to be searched and shared, social media can assist companies to create an online resource containing the accumulated wisdom of the company leading to the new source of consumer influence and empowerment (Culnan et al. 2010)

In addition, research suggests that in order to react effectively to this changing environment, companies need to turn this networking trend for their own benefits, by giving the opportunity to listen to the customer to get information that can be used to further develop their products or services to better address that customer's needs and evolving demands (Bright et al., 2015; Bugshan, 2015; Maecker et al. 2016). Such social media platforms/technologies have opened new opportunities for CRM, communication, and collaboration for global companies wide (Maecker et al. 2016; Poushter, 2016).The adoption of such technologies is less complicated and less costly due to its wide diffusion and technological advances. All suggest that SCRM needs to be related to social media and Web 2.o technology where the interactivity has introduced in businesses the new term 'customer advocacy', measuring not only loyalty, but also the attitude of the customer towards the organisation (Lim et al. 2011). Thus, this question will enable the given information in the survey to be related to social media applications that are currently being in use associated with SCRM for Australian companies.

\subsection{What are Currently SCRM Implementation-Related Activities?}

Despite the growing body of research on SCRM implementation-related activities, existing guidelines for implementing SCRM and the verifiable criteria for its success still lack empirical support. Those research efforts were performed in different business contexts and different countries. Previous research indicates that SCRM generally comprises three fundamental practices and activities including: firstly, creating a tool for efficiently discovering comments and opinions from people/customers in the marketplace about all issues that is related to the organisation; secondly, establishing a contact channel for twoway interaction with people/customers in social networking sites; and finally, providing an integration of content from social networking sites with customer-orientated processes and systems (Harrigan and Miles, 2014; Yoon and Jeanetta, 2014).

To be more specific, social media has the capability of enabling companies to manage unstructured tacit knowledge and bolster business collaboration (Buttle and Maklan, 2015; Malthouse et al. 2013). Consequently, SCRM offers the company to harvest information from social media communities where company can integrate this information into customer profiles (Greenberg, 2010). A social network profile model enabling companies to classify individuals based on the interactive activities in which they participate has also been proposed by some researchers (Bugshan, 2015; Li and Bernhoff, 2008; Nair, 2009). This profile allows companies to better understand how social technologies are being adopted by any group of people, which can help them examine and create targeted strategies based on 
the tendencies of an individual's interactivity (Poushter,2016). This question thus will enable the researcher to explore and investigate the current SCRM implementation related activities within Australian company, and subsequently provide a foundation for determining the usual guidelines for SCRM initiatives in the Australian context.

\subsection{What are the Barriers to SCRM Adoption and Implementation?}

Previous research indicates that that SCRM may not equally benefit all business segments (Cappuccio et al. 2012). The reason for adoption or non-adoption of SCRM among Australian companies may be due to the barriers associated with such an adoption (Marolt et al. 2015). First, for example, one important barrier is how to effectively harness the potential and collective intelligence of SCRM which is constantly evolving in response to a changing environment (Ang 2011; Sumathi et al. 2015). Also, given that SCRM is not merely confined to the technical specifications, but rather involves the company structure, transformations in both of these areas are deemed essential for the adoption of SCRM (Malthouse et al. 2013). Secondly, another barrier could be the lower rate of traditional CRM uptake in Australia and/or because many companies fail to see a return on investment (ROI) of their CRM and found little incremental benefit from the traditional CRM (Ang and Buttle 2006, Peppers and Rogers, 2004).

A previous study conducted by Cappuccio et al. (2012) in Canada, found that only $23 \%$ of private business that implement SCRM do not fully obtain its benefits in adoption of SCRM because the implementation of an effective SCRM solution requires time-consuming, adequate IT resources and finances available for investment. Obviously, setting up of a community for SCRM purposes require both cost-demanding and time-demanding. Thus, companies, particularly smaller companies, may not always afford this change, but rather prefer to use the usual way of doing business to cultivate the customer experience (Cappuccio et al. 2012). Third, as recently reported by the Sensis (2016), although the uptake of social media by Australian companies has continually increased over the years, only around 3opercent of small and medium sized businesses have developed a strategic plan for their social media compared to $76 \%$ of large businesses. This can raise the issue of whether such Australian companies have recognised and adopted SCRM initiatives where social media plays an important role in their existing traditional CRM. This research question will enable the data gathered on SCRM in the survey to a better understanding of the reasons hampering SCRM adoption and implementations.

\section{Research Method}

This study used a quantitative approach based on a survey questionnaire administered via the Internet online survey tool. The 'SurveyMonkey' which has been widely used by major organisations was used to sample 10,000 Australian companies across all sizes and sectors, randomly selected from the population of Australian private companies listed in the Dun \& Bradstreet (Australia) database. As SCRM is closely associated with IT and marketing functions (Huang and Wang 2013), the survey questionnaire was distributed to the ownermanagers including senior managements who could reasonably be expected to have responsibilities covering IT management, marketing management, or both types of management combined.

Given a lack of publicly available data on SCRM in Australian companies, a survey questionnaire for this study was developed based on the extant literature (Acker et al. 2011; Reinhold and Alt. 2012; Cappuccio et al. 2012) and on discussions with senior academic researchers in the fields of IT and marketing who have expertise and familiarity with SCRM practices in the Australian private sector. Then, the proposed questionnaire was pre-tested with three academic researchers who were familiar with SCRM practices in the Australian private sector, and another three senior managers whose main responsibility within their company was in both IT and marketing management (Sekaran, 2003). Their responses were not used in the final research. 
The survey questionnaire, with a total of 22 questions, consisted of three main sections including: Section 1 - Demographic and background information; (ii) Section 2 Information collected for companies that have adopted SCRM; and (iii) Section 3 Information collected for companies that have 'not' adopted SCRM and those that have made no decision on the matter. This research used closed questions in a survey-based format in order to allow responses to be easily classified, thus making analysis straightforward. All questions were worded carefully and avoided ambiguity and jargon. Each closed question contains a list of response items from which the respondent can select his/her answer(s). These response items included closed responses with additional comments such as "other (please specify)". Closed questions were asked, supplemented by comment boxes for gathering additional information. The design of the survey, which protected respondent anonymity with different scale for measurement, was designed to help minimise common method bias - i.e. a variance bias that is attributable to the measurement method rather than to the constructs the measures represent (Podsakoff et al. 2003).

The total number of completed survey responses received was 1,168 (from out of 10,000 targeted companies). Of these completed responses, 108 were eliminated because of missing values. This left a sample of 1,06o final completed responses for the quantitative survey part, representing a 10.6 percent response rate. Specifically, the presence of missing values is a common problem for the analysis of survey data. Of all 1,168 companies responding to the study's survey, 108 (9.25\%) did not give answers to one or more questions. As the proportion of these missing data was small and the values were missing at random, utilising a conservative method - list wise deletion - was appropriate (Allison, 2001; Tabachnick and Fidell 2001). The 108 companies with missing data were therefore excluded from the analyses, reducing the number of valid responses to 1,060 companies. A sample of 1,060 was considered a large validation sample, which is more than sufficient to derive reliable findings and draw meaningful conclusions.

Also, the possibility of non-response bias was assessed through Armstrong and Overton (1977) time-trend extrapolation procedure. This procedure is based on the assumption that persons who respond less readily (or replying later to a survey) are more likely to resemble non-respondents. Differences between early respondents and late respondents thus closely reflect differences between respondents and non-respondents (Armstrong and Overton 1977). Of 1,060 valid responding companies, 844 were classified as early respondents (responding to the survey within 8 weeks after the initial survey distribution) and 216 were classified as late respondents (responding to the survey after an email follow-up was sent out i.e. more than 8 weeks after the initial survey distribution). The chi-square test for independence was performed using IBM SPSS Statistics version 21 to determine if there was any statistically significant difference between these two groups that could bias the research findings. The findings showed no significant difference between early and late respondents in terms of company size(Mean=2.25, $\left.\mathrm{SD}=0.96, X^{2}=5.36, \mathrm{p}=0.147\right)$, industry sector $\left(\mathrm{Mean}=4.20, \mathrm{SD}=1.42, X^{2}=8.52, \mathrm{p}=0.202\right)$, and decision to adopt SCRM $\left(X^{2}=2.68, \mathrm{p}=\right.$ $0.101)$.

\section{Findings and Discussion}

\subsection{Pattern of SCRM Adoption in Australian Companies}

The questionnaire defined traditional CRM as "a business strategy that drives functional plans, processes and actions towards establishing relationships with customers". All respondents were asked if their "company has adopted and/or implemented SCRM, that is, using social media (Facebook, LinkedIn, Twitter, YouTube, Blogs etc.) to enhance [their] traditional CRM".

Of 1 ,060 respondents, $55.2 \%$ had the main job responsibility in both IT and marketing management, $21.2 \%$ in IT management only, and the remaining $23.6 \%$ in marketing management only. Current positions represented were CEO (44.4\%), IT manager (20.0\%), marketing manager (21.8\%) and other (13.8\%). The majority of responding companies had 
their head office located in New South Wales (31.5\%), Victoria (25.0\%), and Queensland (16.1\%) (See Table 1).

Specifically, Table 1 presents the pattern of SCRM adoption in Australian companies. Of 1,060 respondents, $56.3 \%$ reported the adoption of SCRM by their company- of which $32.5 \%$ fully adopted and implemented SCRM, 20.6\% recently adopted SCRM and were in the process of implementation, and 3.2\% adopted SCRM in the past but had now terminated the use of it. These findings showed that SCRM in Australian companies are still at an early stage of adoption. Of note, all of the 597 SCRM adopters also indicated their engagement in at least one of the tradition CRM activities such as determining the needs of existing and potential new customers (cited by 70.0\% of all SCRM adopters), having a formal process to manage customer referrals (55.1\%) and having a formal process for identifying potential customers and their likely value (51.6\%).Meanwhile, of all 1,060 respondents, 43.7\% reported that their company did not adopt SCRM- of which $36.8 \%$ made no decision (or no plan) regarding SCRM while 6.9\% indicated that they would definitely not adopt SCRM. Of all the 463 non-SCRM adopters, 89.2\% indicated their engagement in at least one of the traditional CRM as mentioned above activities.

Table 1 also presents the distribution of companies that adopted, and did not adopt, SCRM by company size and industry sector. For the purpose of this research conducted in the Australian context, the Australian Bureau of Statistics' (ABS 2001) definition of company size based on the number of full-time equivalent employees was used: 'micro' (under 5 employees), 'small' (5-19), 'medium' (20-199), and 'large' (200 or more). In the sample, 31.5\% were micro companies, $59.7 \%$ were small and medium enterprises (SMEs), and $8.8 \%$ were large companies. This is consistent with the company size structure of the Australian economy which is largely characterised by micro companies and SMEs (ABS 2001). The share of companies adopting SCRM slightly increased with the size of the company, where $61.3 \%$ of large companies adopted SCRM, compared to $51.5 \%$ of micro-sized companies. This could be because large companies (compared to smaller counterparts) have more expertise and knowledge and better access to financial and human resources to handle the difficulties

Table 1: Distribution of SCRM adopters and Non-SCRM adopters by company size and industry sector

\begin{tabular}{|c|c|c|c|c|c|c|c|}
\hline Level of SCRM Adoption & $\mathbf{N}$ & $\%$ & & & \multirow[t]{4}{*}{$N$} & \\
\hline Fully adopted and implemented SCRM & 345 & 32.5 & & & & \multicolumn{2}{|c|}{$\begin{array}{l}\text { Percentage (\%) of companies } \\
\text { withineach size class/sector }\end{array}$} \\
\hline Recently adopted SCRM and were in the process of implementation & 218 & 20.6 & & & & $\begin{array}{l}\text { SCRM } \\
\text { Adopters }\end{array}$ & $\begin{array}{l}\text { Non-StRM } \\
\text { adopters(463) }\end{array}$ \\
\hline Adopted SCRM in the past but had now terminated the use of it & 34 & 3.2 & \multirow{3}{*}{ Status } & & & & \\
\hline & 390 & 36.8 & & Adopting SCRM & 597 & 56.3 & - \\
\hline Definitely not adopt SCRM & 73 & 6.9 & & Not adopting SCRM & 463 & - & 43.7 \\
\hline Alt respondents & & & \multirow[t]{5}{*}{ Size } & Micro (under 5) & 334 & 51.5 & 48.5 \\
\hline Respondent's main responsibility at the company & $\mathbf{N}$ & $\%$ & & $\operatorname{Small}(5-19)$ & 223 & 58.8 & 41.2 \\
\hline IT Management & 225 & 21.2 & & Medium (20-199) & 400 & 57.8 & 42.3 \\
\hline Marketing Management & 250 & 23.6 & & Large ( 200 or more) & 93 & 61.3 & 38.7 \\
\hline $\begin{array}{l}\text { Both IT and Marketing Management } \\
\text { All respondents }\end{array}$ & $\begin{array}{c}585 \\
1,060\end{array}$ & $\begin{array}{c}55.2 \\
100.0 \\
\end{array}$ & & Chi-square $(d f=3)$ & \multicolumn{3}{|c|}{$5.01(p=0.171)$} \\
\hline Respondent's current position & $\mathrm{N}$ & $\%$ & \multirow{18}{*}{ Sector } & Agriculture, forestry and fishing & 38 & 63.2 & 36.8 \\
\hline CEO & 470 & 44.4 & & Mining & 10 & 30.0 & 70.0 \\
\hline $\begin{array}{l}\text { IT Manager } \\
\text { Marketing Manager }\end{array}$ & $\begin{array}{r}211 \\
222\end{array}$ & 20.0 & & Manufacturing & 106 & 43.4 & 56.6 \\
\hline $\begin{array}{l}\text { Marketing Manager } \\
\text { Other }\end{array}$ & & $\begin{array}{l}21.8 \\
13.8\end{array}$ & & Electricity, gas, water and waste services & 15 & $53 \cdot 3$ & 46.7 \\
\hline All respondents & 1,060 & 100.0 & & Construction & 68 & 47.1 & 52.9 \\
\hline Company's head office & $\mathbf{N}$ & $\%$ & & $\begin{array}{l}\text { Wholesale trade } \\
\text { Retail trade }\end{array}$ & $\begin{array}{l}64 \\
154\end{array}$ & $\begin{array}{l}46.9 \\
67.5\end{array}$ & $\begin{array}{l}53.1 \\
32.5\end{array}$ \\
\hline Australia Capital Territory & 20 & 1.9 & & Accommodation and food services & 79 & 67.1 & 32.9 \\
\hline New South Wales & 334 & 31.5 & & Transport, postal and warehousing & 25 & 60.0 & 40.0 \\
\hline $\begin{array}{l}\text { Northern Territory } \\
\text { Oueensland }\end{array}$ & 23 & 2.2 & & Information media and telecommunications & 115 & 55.7 & 44.3 \\
\hline $\begin{array}{l}\text { Queensiland } \\
\text { South Australia }\end{array}$ & $\begin{array}{l}171 \\
78\end{array}$ & $\begin{array}{r}10.1 \\
7.4\end{array}$ & & Financial and insurance services & 41 & 53.7 & 46.3 \\
\hline $\begin{array}{l}\text { Tasmania } \\
\text { Taslild }\end{array}$ & 72 & $\begin{array}{l}1.4 \\
6.8\end{array}$ & & Rental, hiring and real estate services & 21 & 42.9 & 57.1 \\
\hline Victoria & 265 & 25.0 & & Professional, scientific and technical services & 136 & 53.7 & 46.3 \\
\hline Western Australia & 87 & 8.2 & & Administrative and support services & 24 & 50.0 & 50.0 \\
\hline Outside of Australia & 10 & 0.9 & & Public administration and safety & 13 & 53.8 & 46.2 \\
\hline \multirow[t]{4}{*}{ All respondents } & \multirow{4}{*}{\multicolumn{2}{|c|}{$1,060100.0$}} & & Education and training & 41 & 61.0 & 39.0 \\
\hline & & & & Health care and social assistance & 61 & 59.0 & 41.0 \\
\hline & & & & Arts and recreation services & 49 & 69.4 & 30.6 \\
\hline & & & & Chi-square $(d f=17)$ & 33. & $(p=0.009$ & \\
\hline
\end{tabular}


associated with SCRM. However, it should be note that chi-square test did not detect a positive size effect $(\mathrm{X} 2=5.01, \mathrm{p}=0.171)$, which could reflect the fact that this test did not control for any other factors that could confound the findings.

The industry sector to which companies belong mattered for SCRM adoption $\left(X_{2}=33.65, p=\right.$ 0.009). The three sectors with the highest share of companies adopting SCRM were arts and recreation services $(69.4 \%$ of companies within the sector), retail trade $(67.5 \%)$, accommodation and food services (67.1\%) and agriculture, forestry and fishing (63.2\%). These findings suggested that these sectors were likely to be among the first group of companies in Australia that moved towards SCRM and that perhaps realised the strategic opportunities offered by such initiative. Sectors with the lower share of SCRM adopters (less than $50 \%$ of companies within the sector) included mining (30\%), rental, hiring and real estate services (42.9\%), manufacturing (43.4\%), wholesale trade (46.9\%), and construction (47.1\%). This may be due to less reliance on company to customer sales.

\subsection{Preliminary Findings in Relation to Research Questions}

As some of the survey questions were not asked of all respondents, the preliminary (descriptive) findings reported in this section need to be divided into two subsections in relation to the two groups of companies: SCRM adopters and non-SCRM adopters. Only these 597 SCRM adopters were subsequently asked three sets of questions, covering: objectives for SCRM engagement; types of social media used with SCRM and SCRM implementation-related activities. Meanwhile, 463 non-SCRM adopters were subsequently asked regarding the barriers to SCRM adoption.

\subsubsection{Objectives for SCRM Engagement}

The findings revealed that the most important objectives for SCRM adoption by Australian companies were to: strengthen a company's brand (81\%), enhance customer loyalty (80.4\%); establish trust-based relationships with customers (79.6\%) and improve interactive communication between the company and customers (71.7\%). The objectives of SCRM rated most often as of low or no importance were: improvement of cross-selling and upselling of product/service offerings (51.8) and reduction of costs of customer services (42.1\%). Although the results show that the top main four objectives of SCRM adoption support the fundamental of traditional CRM, such objectives are considerably different to the SCRM approach, which has the aim to "engage the customer in a collaborative conversation in order to provide mutually beneficial value in a trusted \& transparent business environment"(Greenberg 2009 p. 34). This implies that Australian companies did not have a SCRM strategy in place yet where the focus of SCRM adoption is more on acquiring new customers by using social media to strengthen a company's brand awareness and retaining existing customers. This finding is corresponding with previous research by Harrigan and Miles (2014) which found that the SMEs in England are using social media to complement their CRM activities and the need to strategically combine social media use with CRM activities was required.

\subsubsection{Types of Social Media Used With SCRM}

All of the 597 SCRM adopters indicated the use of one or more SNSs in association with their SCRM initiatives. The list of SNSs used with SCRM reported by SCRM adopters is shown in Table 2. Facebook dominates the social media space (89.3\%), followed by LinkedIn (54.1.8\%), Google+ (53.1\%), Twitter (52.3\%) and YouTube (47.3\%). Instagram and other (Blogs, Pinterest and Flickr) were the least common SNSs employed with SCRM, cited by $11.3 \%$ and $6.5 \%$ respectively.

Table 4.13 shows the breakdown of SNSs used with SCRM by company size. Facebook was dominantly used by over $80 \%$ of companies in each size category, especially in large companies (of which 98.2\% reported the use of Facebook; $\chi 2=14.56, p<0.001$ ). Google+ played an essential part for medium- and large sized companies $\left(\chi_{2}=23.24, p<0.001\right)$, 
whilst LinkedIn was widely used in association with SCRM in micro- and small-sized companies $(\chi 2=39.40, p<0.001)$. The percentage of companies employing Twitter and YouTube with SCRM increased with company size.

Table 2: SNSs used with SCRM by company size

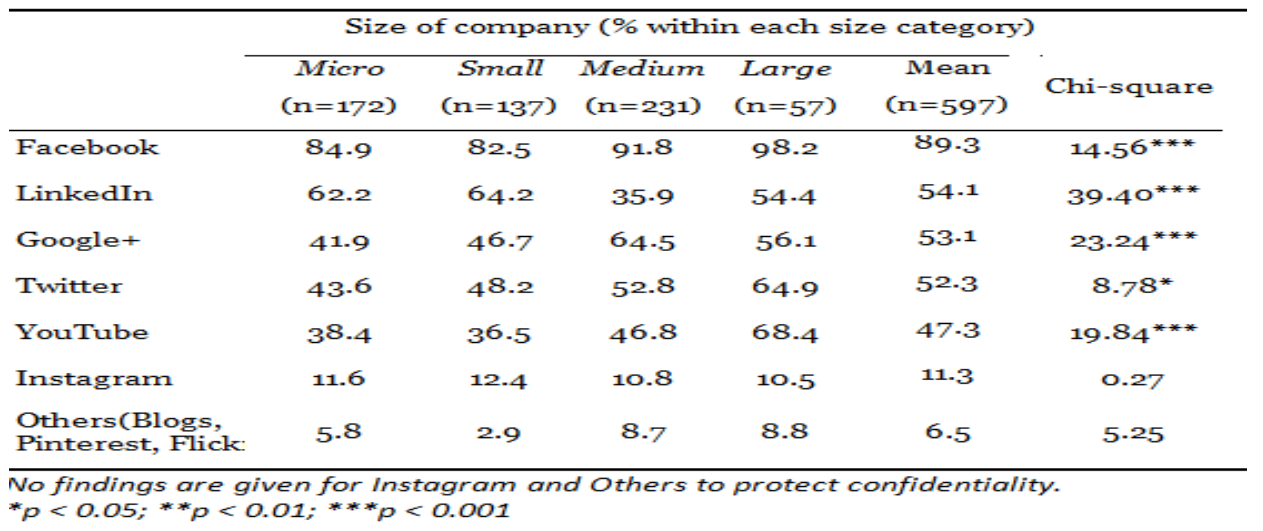

Further findings indicated that some large companies (around 5\%) developed their own internal social network such as Yammer to foster networking among its customers and suppliers or create a private group on LinkedIn as a communication tool.

\subsubsection{SCRM Implementation-Related Activities}

The list of SCRM implementation-related activities reported as undertaken by respondents is shown in Table 4.8. The three most common activities reported by SCRM adopters were monitoring SNSs for comments and conversations regarding the company (72.9\%), learning about social media in the context of customers by creating/collecting customer profiles(64.3\%)and regularly and systematically listening and/or responding to customer comments and conversations on social media regarding the company and its products and services (50.9\%). The two least frequently cited SCRM activities were evaluating/measuring the impact of social media on company findings (33\%) and developing organisational policies/guidelines for the use by staff of SNSs in response to customer comments $(33.2 \%)$. The lesser focus on these two activities could be because of the lack of time and limited knowledge/expertise to effectively select and manage social media tools or SNSs to meet customer needs. Limited time and knowledge, according to the earlier findings (Table 3), were major constraints on implementing SCRM reported by the highest share of SCRM adopters.

Interestingly, within the activity of proactively looking for a new way of using social media to engage with customers, the most popular method across all business sizes was to put links to social media on the company's website (90\%). This implies that companies did not only posted or broadcast useful information on their social media pages, but also put a link that directed to their company's website in order to get people to visit the website, increase online attendance, and receive maximum traffic in turn. Then, such companies analyse conversation data on social media and try to integrate/match such unstructured data with traditional CRM systems for creating new structured data, customer profiles and information about customers. 
Table 3: SCRM implementation-related activities

\begin{tabular}{|c|c|c|}
\hline Activity & $N$ & $\begin{array}{l}\text { Percentage } \\
\text { (\%) of Social } \\
\text { CRM } \\
\text { adopters }\end{array}$ \\
\hline $\begin{array}{l}\text {-Monitoring social media sites for comments and conversations regarding } \\
\text { combanv }\end{array}$ & 435 & 72.9 \\
\hline $\begin{array}{l}\text {-Learning about social media in the context of customers } \\
\text { (e.g. creating/collecting customer profiles) }\end{array}$ & 384 & $64 \cdot 3$ \\
\hline $\begin{array}{l}\text {-Regularly and systematically listening to and possibly responding to } \\
\text { customer comments and conversations on social media regarding company } \\
\text { and its products and service }\end{array}$ & 304 & 50.9 \\
\hline $\begin{array}{l}\text {-Proactively looking for new ways of using social media to engage with } \\
\text { customers. }\end{array}$ & 294 & 49.2 \\
\hline $\begin{array}{l}\text {-Using social media sites to collaborate and co-create content with customers } \\
\text { in order to increase brand engagement }\end{array}$ & 254 & 42.5 \\
\hline $\begin{array}{l}\text {-Planning and identifying ways of analysing and aggregating data from social } \\
\text { media in order to yield summary usable data regarding customers and } \\
\text { products and services }\end{array}$ & 228 & 38.2 \\
\hline $\begin{array}{l}\text {-Finding ways to use the data that companies have uncovered in conversations } \\
\text { and/or that customers have volunteered through their use of social media }\end{array}$ & 207 & $34 \cdot 7$ \\
\hline $\begin{array}{l}\text {-Developing organisational policies and guidelines for the use of social media } \\
\text { by employees in responding to or jointing customer comments and } \\
\text { conversations }\end{array}$ & 198 & 33.2 \\
\hline -Evaluating or measuring social media's impact on company results & 197 & 33.0 \\
\hline All Social CRM adopters & .597 & 100.0 \\
\hline
\end{tabular}

\subsubsection{Barriers to SCRM Adoption and SNSs Used to Interact With Customers}

Non-SCRM adopters were asked to rate the importance of each of the items as barriers to SCRM adoption. The findings indicated that time-related and knowledge-related factors were rated by a majority of Non-SCRM adopters as potential factors deterring them from adopting SCRM. Specifically, of 463 Non-SCRM adopters, 68\% rated time consuming to manage and monitor SNSs as barriers with very high importance, whilst a lack of information on how to effectively implement SCRM (business case), insufficient skills and support form senior management were rated by $44.3 \%, 41.9 \%$ and $34.6 \%$ respectively. Interestingly, around a third of non-SCRM adopters did not consider the misuse by employees of social media tools (35.9\%) and high financial cost (32.8\%) as factors preventing them from adopting SCRM. These barriers should not be interpreted as real impediments, but rather an indication of managers increasingly being aware of the difficulties involved in adopting SCRM or in the learning advantages of direct experience. This implies that such companies did not also have a formal social media strategy and policy in place, while the use of CRM and data-mining techniques can be superficially operated as simple strategies with less sophisticated knowledge bases and management capacity in relation to CRM activities. This could make such companies reluctant and hesitant to further uptake the full-scale SCRM activities.

Based on above findings, there are several implications for practitioners. First, this research suggests although the uptake of SCRM by Australian companies is at the early stage, companies realise the importance of social media tools becoming centres of conversations and idea exchange and attempts to integrate such tools within their daily CRM routines. This can inform the strategic outlook of building companies to capitalise on the early adopter benefits of SCRM use. Second, there are critical points to be considered when planning to invest in SCRM where companies should consider two main issues: a lack of SCRM strategy, and the lack of knowledge in operating new form of technology. By developing a SCRM strategy to define objectives, and allocating resources to achieving those objectives, companies have a clear direction for their future and articulate what they aim to accomplish in a certain period of time. Our recommendation for companies without SCRM experience is to keep an eye on the SCRM related activities of other companies in their industry and attempted to enact such activities in a better and more creative way. Indeed, a key person who has an extensive knowledge in the areas of IT, marketing and CRM in implementing 
SCRM initiative is required. Third, future investment in the SCRM project will depend upon the perception by companies of the benefits from their current social media. Companies must have social media strategy in place and start using social media to segment customers by value such as having different types and levels of SCRM strategy for different customers. This can improve the ROI on social SCRM strategies. Finally, rather than looking at social media as a way to build brand awareness or drive sales, companies may consider embracing SCRM to connect with prospects and establish meaning relationships with existing customers. Creating online community to facilitate transparency in communication between companies and customers will improved relationships leading to the improvement of company's performance.

\section{Conclusions}

This study has presented the preliminary findings of quantitative data analysis. Large-scale survey data with 1,060 responses were analysed using the descriptive statistics with some inferential statistics (logit regression) to explore the current state of SCRM in Australian company's private sector. The findings reveal that SCRM adoption by Australian companies has been relatively superficial and usually not supported by a formal integrated strategy and policy framework. SCRM in the Australia private sector is still in the early stages of adoption, requiring a considerable learning process. The uptake of SCRM has been found to be influenced by company size and industry sector SCRM, as well as barriers to adopting or implementing SCRM (especially the lack of time, relevant knowledge, expertise and top management support). Whilst companies that have adopted SCRM have done so with the expectation of benefits, particularly in terms of building brand and establishing customer loyalty, the research findings show that the benefits of SCRM are often linked with the benefits of social media presence at this stage. As expected, Facebook, LinkedIn Google+, and Twitter are the main SNSs used by majority of Australian companies to support their existing CRM system. At this stage, companies integrate extended social media features into their CRM systems (e.g., links SNSs into companies' website, engaging in conversation, creating/collecting customer profiles, listening and monitoring comments from customers and integrating social media data into CRM system), in order to increase the effectiveness and efficiency of their CRM activities. Overall, Australian companies did not fully adopt SCRM and create it as business strategy rather using as a business guideline by combine social media incorporated with their existing CRM activity.

Due to the explorative nature of this research, the next steps in this project include the identification of the relevant factors influencing the adoption of SCRM by testing relationship between factors such as internal and external factors; and an investigation in depth of such factors by generating insight into factors that support or hinder adoption through the qualitative approach. Future longitudinal research that conducts an in-depth comparison of SCRM initiative and traditional CRM as well as such initiatives adoption in specific industry sectors, company size classes and target customer groups, would also yield useful insights that enhance an understanding of the SCRM phenomenon and support the development of a business case for effective SCRM investment. 


\section{References}

i. ABS, 2001. "Small Business in Australia, Australian Bureau of Statistics,". [Online] Available at: $\quad$ http://www.abs.gov.au/AUSSTATS/abs@.nsf/mf/1321.0 [Accessed 25 September 2016].

ii. Acker, O. et al., 2011. Social CRM: How Companies can Link into the Social Web of Consumers,". Journal of Direct, Data and Digital Marketing, 13(1), pp. 3-10.

iii. $\quad$ Allison, P., 2001. Missing Data. Sage University Papers Series on Quantitative Applications in the social sciences. Thousand Oaks: Sage, CA.

iv. $\quad$ Ang, L., 2011. "Is SCRM really a good social media strategy?. Journal of Database Marketing \& Customer Strategy Management , 18(3), pp. 149-153.

v. Ang, L. \& Buttle, F., 2006. CRM Software Applications and Business Performance. Journal of Database Marketing \& Customer Strategy Management, Volume 14, pp. 4-16.

vi. Armstrong, J. \& Overton, T., 1977. Estimating Nonresponse Bias in Mail Surveys. Journal of Marketing Research, Volume 14, pp. 396-402.

vii. $\quad$ Bright, F., Kleiser, S. \& Grau, S., 2015. Too Much Facebook?: An Exploratory Examination of Social media fatigue. Computers in Human Behaviour, Volume 44, pp. 148-155.

viii. Bugshan, H., 2015. Open Innovation Using Web 2.0 Technologies. Journal of Enterprise Information Management, 28(4), pp. 595-607.

ix. Buttle, F. \& Maklan, S., 2015. Customer Relationship Management: Concepts and Technologies. 3rd ed. UK: Taylor and Francis.

x. $\quad$ Cappuccio, S. et al., 2012. Social CRM for SMEs: Current Tools and Strategy, Contemporary Research on E-business Technology and Strategy, pp 422-435. Berlin Heidelberg: Springer.

xi. Choudhurya, M. \& Harrigan, P., 2014. "CRM to Social CRM: The Integration of New Technologies into Customer Relationship Management. Journal of Strategic Marketing, 22(2), pp. 149-176.

xii. Chugh, R., 2012. Social Networking for Businesses: is it Boon or Bane? . In: P. G. I. Cruz-Cunha, M. Lopes, E. Miranda \& G. Putnik, eds. Handbook of Research on Business Social Networking: Organizational, Managerial, and Technological Dimensions (Volume II). s.l.:IGI Global, pp. 603-618.

xiii. Culnan, M., McHugh, P. \& Zubillaga, J., 2010. How Large U.S. Companies can use Twitter and Other Social Media to Gain Business Value. MIS Quarterly Executive , 9(4), pp. 243-259.

xiv. Greenberg, P., 2010. The Impact of CRM 2.0 on Customer Insight. The Journal of Business \& Industrial Marketing, 25(6), pp. 410-419.

xv. Harrigan, P. \& Miles, M., 2014. From e-CRM to s-CRM: Critical Factors Underpinning the Social CRM Activities of SMEs. Small Enterprise Research, Volume 21, pp. 99-116.

xvi. Huang, M. \& Wang, E., 2013. Marketing Is from Mars, IT is from Venus: Aligning the Worldviews for Firm Performance. Decision Sciences, Volume 44, pp. 87-125.

xvii. Kaplan, A. \& Haenlein, M., 2010. Users of the World, Unite! the Challenges and Opportunities of social media. Business Horizons, 53(1), pp. 59-68.

xviii. Komito, L., 2011. Social Media and Migration: Virtual Community 2.o. Journal fo The American Society for Information Science and Technology , 62(6), pp. 1075-1086.

xix. $\quad$ Küpper, T., Lehmkuhl, T., Wieneke, A. \& Jung, R., 2015. Technology Use of Social Media within Customer Relationship Management: An Organizational Perspective. Singapore, 9th Pacific Asia Conference on Information Systems.

xx. Li, C. \& Bernhoff, J., 2008. Groundswell: Winning in a World Transformed by Social Technologies. USA: Forrester Research Inc. 
xxi. Lim, S., Saldana, A. \& Saldana, P., 2011. Do Market Oriented Firms Adopt Web 2.0 Technologies? An Empirical Study in Hospitality Firms. International Entrepreneurship and Management Journal, 7(4), pp. 465-477.

xxii. Maecker, O., Barrot, C. \& Becker, J., 2016. The Effect of Social Media Interactions on Customer Relationship Management. Business Research, 9(1), pp. 133-155.

xxiii. Malthouse, E. et al., 2013. Managing Customer Relationships in the Social Media Era: Introducing the Social CRM House. Journal of Interactive Marketing, 27(4), pp. 270-280.

xxiv. Marolt, M., Pucihar, A. \& Zimmermann, H., 2015. Social CRM Adoption and Its Impact on Performance Outcomes: A literature review. Organizacija, Volume 48, pp. 260-271.

xxv. Mosadegh, M. \& Behboudi, M., 2011. Using Social Network Paradigm for Developing a Conceptual Framework in CRM. Australian Journal of Business and Management Research, 1(4), pp. 63-71.

xxvi. Nair, J., 2009. Social Networking on the Generation Next. SCMS Journal of Indian Management, 6(3), pp. 43-52.

xxvii. $\quad$ Peppers, D. \& Rogers, M., 2004. Managing customer relationships: a strategic framework. New Jersey: Wiley.

xxviii. Podsakoff, P., MacKenzie, S., Lee, J. \& Podsakoff, 2003. Common Method Variance in Behavioral Research: A Critical Review of the Literature and Recommended Remedies. Journal of Applied Psychology, 88(5), pp. 879-903.

xxix. $\quad$ Poushter, J., 2016. Smartphone Ownership and Internet Usage Continues to Climb in Emerging Economies-But Advanced Economies till have Higher Rates of Technology Use. [Online] Available at: http://www.pewglobal.org/files/2016/02/pew research center global technology report fi nal february 22 2016.pdf[Accessed 14 January 2017].

xxx. $\quad$ Reinhold, O. \& Alt, R., 2012. Social Customer Relationship Management: State of the Art and Learnings from Current Projects. Slovenia, 25th Bled eConference.

xxxi. $\quad$ Sekaran, U., 2003. Research Methods for Business: A Skill Building Approach. 4th ed. New Jersey: John Wiley and Sons, Inc.

xxxii. Stone, M., 2009. Staying Customer-Focused and Trusted: Web 2.0 and Customer 2.0 in Financial services. Journal of Database Marketing \& Customer Strategy Management, 16(2), pp. 101-131.

xxxiii. Sumathi, C., Jambulingam, M. \& Rajagopal, R., 2015. Issues and Challenges on Venturing into Facebook Commerce. Research Journal of Applied Sciences, Engineering and Technology, 10(11), pp. 1311-1315.

xxxiv. Tabachnick, B. \& Fidell, L., 2001. Using multivariate statistics. 4th ed. Boston: MA: Allyn \& Bacon.

xxxv. Woodcock, N., Green, A. \& Starkey, M., 2011. Social CRM as a Business Strategy. Journal of Database Marketing \& Customer Strategy Management , 18(1), pp. 50-64.

xxxvi. Yawised, K. \& Marshall, P., 2015. Social CRM: A Review of the Literature and the Identification of New Research Directions. International Journal of Virtual communities and Social Networking, 7(1), pp. 14-20.

xxxvii. Yoon, K. \& Jeanetta, S., 2014. Integrating Social Media and Traditional CRM: Toward a Conceptual Framework for Social CRM Practices, Harnessing the Power of Social Media and web analytics, s.l.: IGI Global. 